\title{
Experimental Research Scheme on Fine-Silt Sand Moisture Content Affecting the Failure Behavior of Soil surrounding the CEP Pile
}

\author{
Yongmei Qian ${ }^{1,2 a}$, Yang Yu ${ }^{1 \mathrm{~b}}$, Xiaopeng Su${ }^{3 \mathrm{c}}$, Ruozhu Wang ${ }^{1 \mathrm{~d}}$, \\ a654675316@qq.com, b394845177@qq.com,, '953517776@qq.com, d306109357@qq.com, \\ (1 Jilin Jianzhu University, 2 JilinStructure and Earthquake Resistance Technology Innovation \\ Center, \\ 3 Northeast Electric Power Design Institute Co. LTD of China Power Engineering Consulting \\ Group, Changchun, China)
}

Keywords: the fine-silty sand soil; the moisture content; the CEP(concrete expanded-plates) pile; model experiment; half circle-section pile

\begin{abstract}
Due to the moisture content of fine-silty sand soil has a significant influence for the failure behavior of the soil surrounding the CEP(concrete expanded-plates) pile. In view of the domestic research situation of the CEP pile in current time,this paper preliminarily determines the scheme of half circle-section pile little model which can be conduct with observation experiments,the moisture content of fine-silty sand soil is regarded as a single control variable,by setting the bearing plate in the fine-silty sand soil,carry out the experimental analysis, observe the failure behavior of soil surrounding the pile, and summarize the feasibility and existing problems of the experiment.Thus providing reliable basis to the experimental research which the CEP pile is in the fine-silty sand soil.
\end{abstract}

\section{Introduction}

In recent years, the theory research and experimental research related to the CEP pile in our country is gradually mature. It has already made a detailed elastic-plastic finite element analysis to the parameter of the concrete MEEP Pile, the experimental researches to the failure mechanism of soil surrounding the MEEP Pile with pile plates in different diameter, form, number and spacing[1]. Also, in order to study the ultimate bearing capacity of the MEEP Pile, it is used that the slip line theory, combined with the virtual work principle to determine the ultimate bearing capacity of the MEEP Pile, and to put forward and correct the formula of single pile bearing capacity of the MEEP Pile[2].

At present, the study of CEP pile is mostly aimed at the clayey soil, this situation is fully considered that the characteristic of the clay soil bearing capacity is high, however, due to the geological condition is complicated in engineering application, actual project proves that pile of this type may be set in the fine-silty sand soil, so the study of fine-silty sand soil layer need to be further perfect to meet the needs of practical engineering. Moisture content is an important physical and mechanical indexes of soil, the change of moisture content is related to the cohesive force, internal friction angle, density and other important indicators of soil. The differences of soil moisture content have certain influences for the effect between pile and soil, bearing capacity of the pile and failure mechanism of soil surrounding the CEP pile[3]. In this test, the pile body is placed respectively and completely in fine-silty sand soil layer with the same moisture content, multiple group experiments are carried out. In this paper, according to 
the actual situation, it is preliminary designed the experimental method of half circle-section pile model, put forward the model experimental scheme of fine-silty sand soil moisture content affecting the failure behavior of soil and bearing capacity of CEP pile, and then it is advanced to the feasibility of the model pile experiment in the soil undisturbed. Providing the valuable and reliable experience of experimental study of the CEP pile in the future, to make the design of CEP pile more reasonable in actual engineering.

\section{The small model experimental scheme in half circle-section pile}

Although there has been a small half circle-section pile model experiment in the laboratory and the equal scale practical experimental experience on the site, however, due to the characteristics of fine-silty sand soil are quite different from the clay, therefore, in the design of the experimental scheme, there are many problems need to be focused on. In order to adapt to the soil characteristics, this small model experiment uses the method of soil undisturbed. Specifically includes the following aspects.

\section{The size of model specimens}

Due to the experiment uses the small scale and half circle-section pile model specimens, in the experiment, it is assumed that the pile will not be destroyed while soil is destroyed in the first place, and the specimen material have little impact on test results, therefore, the model pile which is half circle-section of iron pile with bearing enlarging disk, is adopted to conduct the experiment[4]. In the experiment, the length of model pile used is $136 \mathrm{~mm}$, the diameter of pile body is $10 \mathrm{~mm}$, the bearing plate is placed in the middle part along the pile body, the diameter of the plate is $30 \mathrm{~mm}$, the slope angle of it is $39^{\circ}$. The model pile size and side elevation is shown

in Figure 1. According to the requirement of the experiment, considering the pile length, the burial depth of the pile and the influence range of model pile under vertical tension force, the diagram of the placing soil device adopted as shown in Figure 2, the placing soil device is composed with the steel plate, the glass is placed at the side for embedding pile, the method of bolt connection is used for every steel plate, which can be removed, and is beneficial to the operation of embedding pile before the experiment.

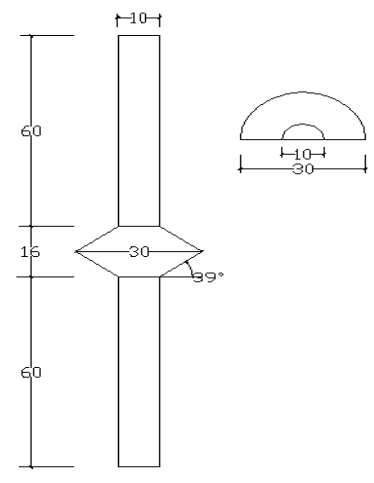

Figure 1 The diagram of model pile specification diagram
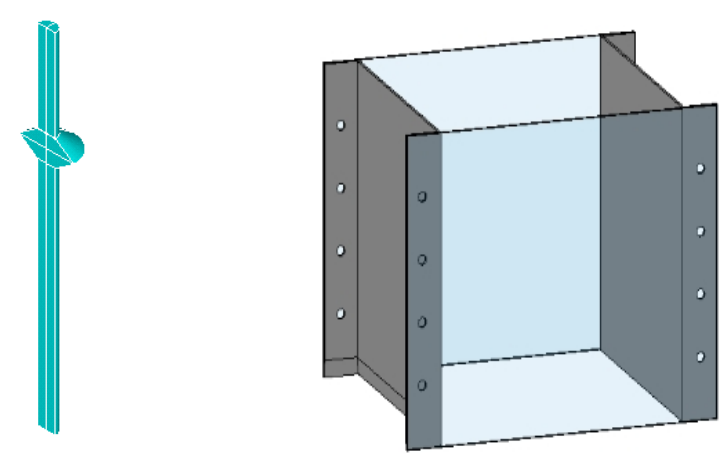

Figure 2 The placing soil device 
The production of experiment specimen and experiment apparatus. The experiment should be conducted in fine-silty sand soil, in order to obtain sandy soil model with different moisture content, it can respectively be put the sand soil samples with different degrees of water, immediately to measure the relative parameters of sand after the experiment. Before the experiment, the prepared sand soil has been embedded in the placing soil device with controlling the moisture content in the process of placing the soil, so the different soil experiment samples are produced and the number of the samples are signed. In order to observe the change trend of soil surrounding the pile clearly, when fastening the placing soil device, of which one side is opened, then to embed the model pile in the sand soil samples which had been made before, then to flat planting the surface of model pile and sand soil sample, finally to install the thick glass, form the experiment specimen to be loaded.

Experiment apparatus. Due to the model specimen is pretty small, so the manual loading is adopted with the adoption of $2 t$ hydraulic jack (as shown in Figure 3), the displacement meter is used to measure the change value of displacement of the pile at the top of the pile in the process of loading step by step (as shown in Figure 4), the fixed card holder (as shown in Figure 5), electronic scale is used to measure the block added to the pile head and jack's own weight, the digital camera used to shoot the failure form and pile soil condition of soil surrounding the model pile before and after loading, the machine to load the specimen is as shown in Figure 6 .

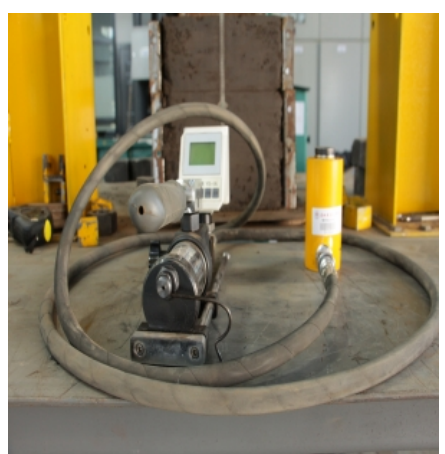

Figure 3 Hydraulic jack

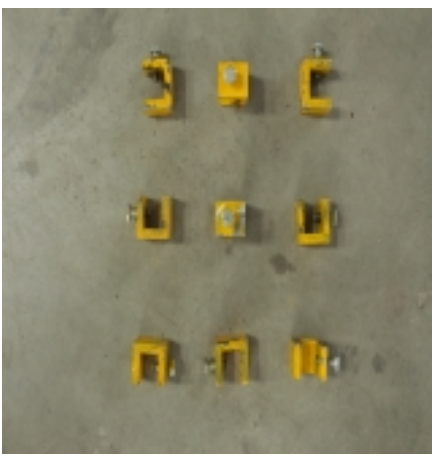

Figure 5 Fixed card holder

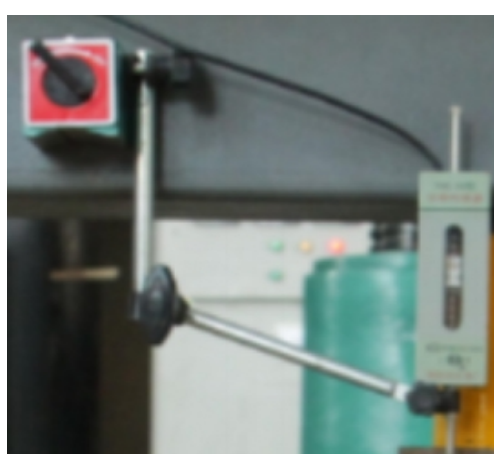

Figure 4 Displacement meter

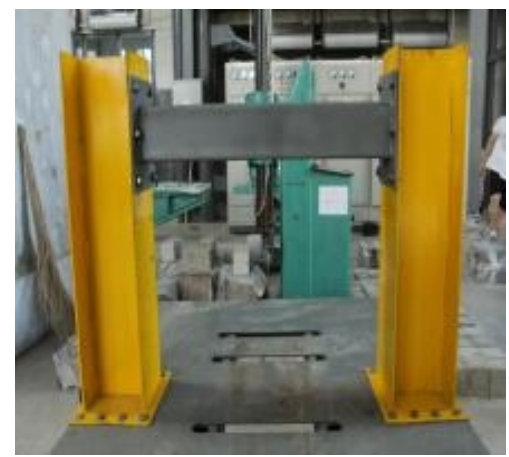

Figure 6 The loaded machine for specimen

\section{The experimental process}

In order to ensure the accuracy of the experiment data, to fix the prepared specimen which is waiting for being loaded on the loaded machine, and take measures to ensure the placing soil device is not deformed, ensure the vertical degree of the load, avoid specimen to lean in loading process, the prophase work must be well-prepared before the experiment can be carried out. 
Putting the block, hydraulic jack, and displacement meter at the top of the pile, also fix and debug them, shoot the pile soil condition with the digital camera before the experiment, to prepare for loading step by step.

Using manual loading step by step, at the same time recording the load of each level and the displacement value of pile top, and shoot the change condition of soil surrounding the pile with the digital camera, continuous loading until it is damaged.

Describing the failure form of the soil surrounding the model pile in time after the completion of loading.

Extracting the soil samples, conduct the geotechnical test of the soil samples, obtain the corresponding data, especially the moisture content value.

Arranging the experiment data, to proceed comparative analysis.

\section{The key points and existing problems of ensuring the success of experiment.}

\section{The key point of ensuring the success of the experiment.}

According to the geological survey of engineering practice, it is more appropriate when the moisture content at about 20\%, the significance of studying stress mechanism when the moisture content is extremely low and high is not big, it should be chosen a suitable moisture content condition for the research[5]. Therefore, it must be noticed when making model samples, it can not be formed the soil sample which moisture content is too big or too small, otherwise may lead to a model test can not reach the expected objects.

In preparation of the test, It should be kept that the verticality of the model pile buried in sand soil samples when burying the pile, in order to avoid the model pile to lean and further cause the experiment failure. At the same time, it should be ensured that there is a certain thickness between the model pile plate and the surface of sandy soil in the placing soil device when burying the pile, and avoiding the model pile to occur punching shear failure under vertical tension[6].

Due to the experiment is manually loaded, during the phase of experiment loading, the speed of the hydraulic jack that loading step by step needs to be controlled, to avoid loading too quickly and led to the deviation of experiment data.

Because the experiment is mainly research the failure behavior of soil surrounding the model pile and the bearing capacity of the model pile under vertical force, it needs to be considered a certain range of soil surrounding the pile, so dimensions of the placing soil device need to be reasonable, to ensure that it can be fully observed the condition of piles and soil in the loading process of model pile.

\section{The existing problems of the experiment}

Because the model experiment adopts the fine-silty sand in which the model pile is embedded, so there is a difference between the soil surrounding the pile in the experiment and the undisturbed soil in actual engineering. And there are some inevitable errors in some aspects such as small model steel piles and model proportion that used in the experiment, it could lead parts of the data that obtained from the test to be biased, so the inevitable errors should be taken into the consideration when coming to the conclusion, but observation of the soil failure behavior basically will not be affected. 
The experimental research is limited to the condition that the pile body is completely set in the fine-silty sand soil layer, however, the subsoil in practical engineering is more complex, there may be many kinds of soil layer at the same time such as cohesive soil, sand soil and so on, so a great deal of research in this area will be needed, in order to provide better service to the engineering practice.

\section{Conclusion}

In recent years, Chinese scholars have done a certain theoretical research and experimental research to the CEP pile, its theoretical achievements and construction technology also gradually mature, the research on presents characteristics of the CEP pile are changed from qualitative to quantitative[7]. In this paper, a preliminary model experiment scheme is established in fine-silt soil with half circle-section pile, further lay the foundation for the experimental research on the influence of soil layer properties for the destruction behavior of soil, experimental research on the influence of the moisture content of fine-silty sand soil for the bearing capacity of the CEP pile is aimed at observing the failure behavior of soil, so the model experiment adopts the model specimen with a small proportion of half circle-section pile, and the buried soil experimental method is used to base on the characteristics of the soil, this method improves the disadvantage of traditional method which only measured data but not to observe the changes trend of soil surrounding the pile during the experiment, through the experimental research, it can be conclude the bearing capacity of the CEP pile, the failure behavior of soil surrounding the pile and the effect between pile and soil, can be clearly observed in the entire change process in loading to failure, and provided a large number of experimental data for the bearing capacity calculation of the subsequent CEP pile, improved the theoretical results of bearing capacity of single pile under vertical load, and provided references for the research of other deformed section piles, and a reliable foundation for the application of the CEP pile in practical engineering, contributed to the research and application of the pile foundation.

\section{Acknowledgments}

This work is financially supported by National Natural Science Foundation of China (51278224).

This work is financially supported by The Education Department of Jilin Province of China ([2016]151).

\section{References :}

[1] Yongmei Qian,Xinsheng Yin,Ruozhu Wang,Xiuxia Yao. Analysis on the Influence of the Bearing

Enlarging Disk Position for the Single Pile Bearing Capacity of the MEEP Pile.

[2] Yongmei Qian,Xinsheng Yin,etc.Apply the Theory of Slip Line to Determine the Calculation

Model of Soil Stress Under the Plate of the MEEP Pile.[J].Journal of Jilin University(Earth

Science Edition), 2004,34:57 - 90 . 
[3] Research on Low Moisture Content and Unsaturated Soil Shear Strength[J] Qingsong Mu,Chongwu Ma,Tiande Miao.Journal of Geotechnical Engineering,2004.26(5):674-678

[4] Experimental Research on Failure Mechanism of Soil of the MEEP Pile.Yongmei Qian,Xinsheng

Yin,Chunling Zhong,Ruozhu Wang,Ping Pang.Geotechnical Engineering Field.2003.6(12)78-80

[5] Research on the Influence of Soil Properties for the Failure Behavior and Bearing Capacity of the

MEEP Pile[M]. Xuewen Xie,Jilin Jianzhu University,2015.6

[6] Research on the Effect of Piles and the Soil Bearing Capacity of the MEEP Pile[D].Jilin University Library,2002

[7] An Overview of the Development of the Experimental Research of the MEEP Pile. Yongmei Qian,Guanghan Xu.2014.41(11)22-24 